\title{
Alkali Metal Cation Affinities of Neutral Maingroup-Element Hydrides across the Periodic Table
}

\author{
Published as part of The Journal of Physical Chemistry virtual special issue "Paul Geerlings Festschrift". \\ Zakaria Boughlala, ${ }^{\dagger}$ Célia Fonseca Guerra, ${ }^{\dagger} \ddagger$ and F. Matthias Bickelhaupt ${ }^{*}, \dagger, \S_{\odot}$ \\ ${ }^{\dagger}$ Department of Theoretical Chemistry and Amsterdam Center for Multiscale Modeling (ACMM), Vrije Universiteit Amsterdam, \\ De Boelelaan 1083, NL-1081 HV Amsterdam, The Netherlands \\ ${ }^{\ddagger}$ Leiden Institute of Chemistry, Leiden University, PO Box 9502, NL-2300 RA Leiden, The Netherlands \\ ${ }^{\S}$ Institute of Molecules and Materials, Radboud University, Heyendaalseweg 135, NL-6525 AJ Nijmegen, The Netherlands
}

\section{Supporting Information}

ABSTRACT: We have carried out an extensive quantum chemical exploration of gasphase alkali metal cation affinities (AMCAs) of archetypal neutral bases across the periodic system using relativistic density functional theory. One objective of this work is to provide an intrinsically consistent set of values of the $298 \mathrm{~K}$ AMCAs of all neutral maingroup-element hydrides $\mathrm{XH}_{n}$ of groups 15-18 along the periods 1-6. Our main purpose is to understand these trends in terms of the underlying bonding mechanism using Kohn-Sham molecular orbital theory together with a canonical energy decomposition analysis (EDA). We compare the trends in $\mathrm{XH}_{n} \mathrm{AMCAs}$ with the trends in $\mathrm{XH}_{n}$ proton affinities (PAs). We also examine the differences between the trends in AMCAs of the neutral $\mathrm{XH}_{n}$ bases with those in the corresponding anionic $\mathrm{XH}_{n-1}{ }^{-}$bases. Furthermore, we analyze how the cation affinity of our neutral Lewis bases changes along the group-1 cations $\mathrm{H}^{+}, \mathrm{Li}^{+}, \mathrm{Na}^{+}, \mathrm{K}^{+}, \mathrm{Rb}^{+}$, and $\mathrm{Cs}^{+}$.

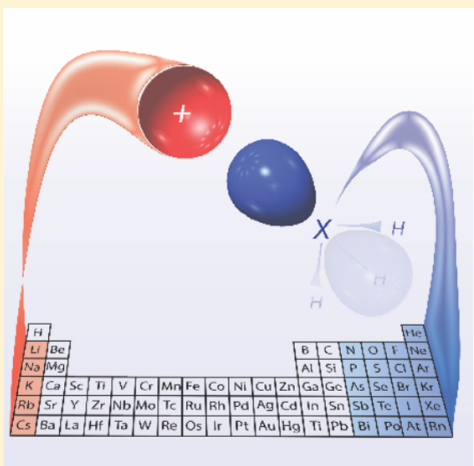

\section{INTRODUCTION}

Alkali metal cations are involved in many chemical and biological systems, such as in osmotic systems, electrolyte balances, ion channels, and electrochemistry. ${ }^{1-9}$ The thermodynamic affinity of Lewis bases for these cations, therefore, plays a significant role for predicting and understanding stability as well as reactivity in various molecular structures and chemical processes, for example, in ion-pair $S_{\mathrm{N}} 2$ reactions. ${ }^{10-13}$ The alkali metal cation affinity (AMCA) is defined as the enthalpy change associated with heterolytic dissociation of the alkali cation $\left(\mathrm{M}^{+}\right)$complex of the neutral $\left(\mathrm{XH}_{n}\right)$ or anionic $\left(\mathrm{XH}_{n-1}^{-}\right)$Lewis base, as shown in eqs 1 and 2 , respectively:

$$
\begin{array}{ll}
\mathrm{MXH}_{n}^{+} \rightarrow \mathrm{M}^{+}+\mathrm{XH}_{n} & \Delta H=\mathrm{AMCA} \\
\mathrm{MXH}_{n-1} \rightarrow \mathrm{M}^{+}+\mathrm{XH}_{n-1}^{-} & \Delta H=\mathrm{AMCA}
\end{array}
$$

Despite the importance of this quantity, relatively little attention has been devoted to the AMCA if compared to, for example, the proton affinity (PA). ${ }^{14-19}$ Nevertheless, there were some theoretical $^{20-30}$ and experimental ${ }^{31-40}$ attempts to better understand the trends and the features behind this quantity.

In our previous study, ${ }^{41}$ we found that the AMCAs of the anionic maingroup-element hydrides $\left(\mathrm{XH}_{n-1}{ }^{-}\right)$(eq 2) are significantly smaller than the corresponding proton affinities (PAs) and show similar although not identical trends, compared to PAs, if the Lewis-basic center $\mathrm{X}$ varies across the periodic table. The reason for the smaller AMCA is mainly a much weaker HOMO-LUMO interaction between the Lewis base and the alkali metal cations if compared to the proton. ${ }^{42}$ This is due to the increase in the HOMO-LUMO gap and the decrease in the HOMO-LUMO overlap as the cation LUMO goes up in orbital energy and becomes more diffuse from proton 1 s to alkali cation $n \mathrm{~s}$ AO.

The present study extends our previous work in three ways: First, we shift our focus from the anionic Lewis bases $\mathrm{XH}_{n-1}$ to the neutral maingroup-element hydrides $\mathrm{XH}_{n}$. The main objective is to obtain a better understanding of the physical factors behind the trends in AMCA values across the periodic table based on a consistent set of accurate data in combination with detailed bonding analyses using Kohn-Sham molecular orbital (KS-MO) theory and a quantitative energy decomposition analysis (EDA). In addition to the AMCAs of all bases $\left(\Delta H_{298}\right)$, we also report the associated $298 \mathrm{~K}$ entropies $\left(\Delta S_{298}\right.$, provided as $\left.-T \Delta S_{298}\right)$ and $298 \mathrm{~K}$ Gibbs energies $\left(\Delta G_{298}\right)$. In the second place, we wish to compare the AMCAs of the neutral bases $\left(\mathrm{XH}_{n}\right)$ with both the PAs of the neutral bases $\left(\mathrm{XH}_{n}\right)^{14-16}$ as well as the AMCAs of the corresponding anionic bases $\left(\mathrm{XH}_{n-1}{ }^{-}\right){ }^{41}$ Third, we examine how the cation

Received: April 24, 2019

Revised: July 10, 2019

Published: July 11, 2019 
Table 1. Thermodynamic PA and AMCA Properties (in $\mathrm{kcal} \mathrm{mol}^{-1}$ ) for Neutral Maingroup-Element Hydrides at $298 \mathrm{~K}^{a}$

\begin{tabular}{|c|c|c|c|c|c|c|c|c|c|c|c|c|c|c|c|c|}
\hline \multirow[b]{2}{*}{ period } & \multicolumn{4}{|c|}{ group 15} & \multicolumn{4}{|c|}{ group 16} & \multicolumn{4}{|c|}{ group 17} & \multicolumn{4}{|c|}{ group 18} \\
\hline & base & $\Delta \mathrm{H}$ & $-T \Delta S$ & $\Delta G$ & base & $\Delta \mathrm{H}$ & $-T \Delta S$ & $\Delta G$ & base & $\Delta \mathrm{H}$ & $-T \Delta S$ & $\Delta G$ & base & $\Delta \mathrm{H}$ & $-T \Delta S$ & $\Delta G$ \\
\hline \multicolumn{17}{|c|}{ Proton Affinities } \\
\hline $\mathrm{P} 1$ & & & & & & & & & & & & & $\mathrm{He}$ & 45.2 & -5.9 & 39.3 \\
\hline $\mathrm{P} 2$ & $\mathrm{NH}_{3}$ & 203.4 & -8.2 & 195.2 & $\mathrm{OH}_{2}$ & 164.7 & -7.4 & 157.3 & $\mathrm{FH}$ & 117.6 & -6.5 & 111.0 & $\mathrm{Ne}$ & 52.7 & -5.6 & 47.0 \\
\hline P3 & $\mathrm{PH}_{3}$ & 185.8 & -8.2 & 177.6 & $\mathrm{SH}_{2}$ & 170.6 & -7.5 & 163.1 & $\mathrm{ClH}$ & 136.2 & -6.4 & 129.8 & $\mathrm{Ar}$ & 93.9 & -5.3 & 88.5 \\
\hline P4 & $\mathrm{AsH}_{3}$ & 176.7 & -8.2 & 168.5 & $\mathrm{SeH}_{2}$ & 172.4 & -7.5 & 164.9 & $\mathrm{BrH}$ & 141.9 & -6.3 & 135.6 & $\mathrm{Kr}$ & 106.1 & -5.2 & 100.9 \\
\hline P5 & $\mathrm{SbH}_{3}$ & 175.5 & -8.1 & 167.4 & $\mathrm{TeH}_{2}$ & 178.5 & -7.4 & 171.0 & $\mathrm{IH}$ & 151.9 & -6.2 & 145.7 & $\mathrm{Xe}$ & 122.3 & -5.1 & 117.2 \\
\hline P6 & $\mathrm{BiH}_{3}$ & 161.4 & -8.1 & 153.3 & $\mathrm{PoH}_{2}$ & 180.9 & -7.4 & 173.5 & AtH & 156.1 & -6.2 & 149.9 & $\mathrm{Rn}$ & 129.2 & -5.0 & 124.2 \\
\hline \multicolumn{17}{|c|}{ Lithium Cation Affinities } \\
\hline P1 & & & & & & & & & & & & & $\mathrm{He}$ & 1.7 & -4.6 & -2.9 \\
\hline $\mathrm{P} 2$ & $\mathrm{NH}_{3}$ & 37.4 & -7.1 & 30.2 & $\mathrm{OH}_{2}$ & 32.1 & -6.8 & 25.4 & $\mathrm{FH}$ & 21.5 & -5.8 & 15.7 & $\mathrm{Ne}$ & 2.7 & -4.5 & -1.8 \\
\hline P3 & $\mathrm{PH}_{3}$ & 23.2 & -6.0 & 17.2 & $\mathrm{SH}_{2}$ & 22.2 & -6.2 & 16.0 & $\mathrm{ClH}$ & 15.7 & -5.4 & 10.3 & $\mathrm{Ar}$ & 6.7 & -4.7 & 2.0 \\
\hline P4 & $\mathrm{AsH}_{3}$ & 19.6 & -6.6 & 13.0 & $\mathrm{SeH}_{2}$ & 22.4 & -6.2 & 16.2 & $\mathrm{BrH}$ & 16.2 & -5.3 & 10.9 & $\mathrm{Kr}$ & 8.3 & -4.6 & 3.7 \\
\hline P5 & $\mathrm{SbH}_{3}$ & 17.8 & -6.4 & 11.4 & $\mathrm{TeH}_{2}$ & 23.0 & -6.0 & 17.0 & $\mathrm{IH}$ & 17.3 & -5.2 & 12.1 & $\mathrm{Xe}$ & 10.5 & -4.6 & 6.0 \\
\hline P6 & $\mathrm{BiH}_{3}$ & 11.4 & -6.2 & 5.2 & $\mathrm{PoH}_{2}$ & 23.7 & -6.1 & 17.6 & AtH & 18.1 & -5.2 & 12.9 & $\mathrm{Rn}$ & 11.8 & -4.5 & 7.3 \\
\hline \multicolumn{17}{|c|}{ Sodium Cation Affinities } \\
\hline $\mathrm{P} 1$ & & & & & & & & & & & & & $\mathrm{He}$ & 0.8 & -3.9 & -3.1 \\
\hline P2 & $\mathrm{NH}_{3}$ & 25.7 & -6.8 & 18.9 & $\mathrm{OH}_{2}$ & 21.8 & -6.4 & 15.4 & $\mathrm{FH}$ & 14.5 & -5.3 & 9.3 & $\mathrm{Ne}$ & 1.2 & -3.6 & -2.4 \\
\hline P3 & $\mathrm{PH}_{3}$ & 15.4 & -6.3 & 9.2 & $\mathrm{SH}_{2}$ & 14.7 & -5.9 & 8.9 & $\mathrm{ClH}$ & 9.9 & -5.0 & 4.9 & $\mathrm{Ar}$ & 3.5 & -4.3 & -0.7 \\
\hline P4 & $\mathrm{AsH}_{3}$ & 12.6 & -6.2 & 6.4 & $\mathrm{SeH}_{2}$ & 15.1 & -5.9 & 9.2 & $\mathrm{BrH}$ & 10.3 & -5.0 & 5.3 & $\mathrm{Kr}$ & 4.6 & -4.3 & 0.4 \\
\hline P5 & $\mathrm{SbH}_{3}$ & 11.2 & -6.0 & 5.3 & $\mathrm{TeH}_{2}$ & 15.9 & -5.7 & 10.2 & $\mathrm{IH}$ & 11.2 & -4.9 & 6.3 & $\mathrm{Xe}$ & 6.2 & -4.2 & 2.0 \\
\hline P6 & $\mathrm{BiH}_{3}$ & 6.1 & -5.7 & 0.4 & $\mathrm{PoH}_{2}$ & 16.7 & -5.8 & 10.9 & AtH & 11.9 & -4.9 & 7.0 & $\mathrm{Rn}$ & 7.1 & -4.2 & 2.9 \\
\hline \multicolumn{17}{|c|}{ Potassium Cation Affinities } \\
\hline P1 & & & & & & & & & & & & & $\mathrm{He}$ & 0.4 & -2.8 & -2.4 \\
\hline $\mathrm{P} 2$ & $\mathrm{NH}_{3}$ & 17.8 & -6.4 & 11.4 & $\mathrm{OH}_{2}$ & 15.7 & -6.0 & 9.6 & $\mathrm{FH}$ & 10.7 & -5.2 & 5.5 & $\mathrm{Ne}$ & 0.9 & -4.1 & -3.2 \\
\hline P3 & $\mathrm{PH}_{3}$ & 9.6 & -5.7 & 3.9 & $\mathrm{SH}_{2}$ & 9.3 & -5.3 & 4.0 & $\mathrm{ClH}$ & 6.3 & -4.6 & 1.7 & $\mathrm{Ar}$ & 1.9 & -3.9 & -2.0 \\
\hline P4 & $\mathrm{AsH}_{3}$ & 7.3 & -4.9 & 2.4 & $\mathrm{SeH}_{2}$ & 9.3 & -5.4 & 3.9 & $\mathrm{BrH}$ & 6.3 & -4.6 & 1.7 & $\mathrm{Kr}$ & 2.6 & -4.0 & -1.4 \\
\hline P5 & $\mathrm{SbH}_{3}$ & 5.9 & -4.5 & 1.4 & $\mathrm{TeH}_{2}$ & 9.7 & -5.2 & 4.5 & $\mathrm{IH}$ & 6.8 & -4.4 & 2.4 & $\mathrm{Xe}$ & 3.5 & -4.0 & -0.4 \\
\hline P6 & $\mathrm{BiH}_{3}$ & 1.9 & -4.4 & -2.5 & $\mathrm{PoH}_{2}$ & 10.2 & -5.3 & 4.8 & AtH & 7.2 & -4.5 & 2.7 & $\mathrm{Rn}$ & 4.1 & -3.9 & 0.2 \\
\hline \multicolumn{17}{|c|}{ Rubidium Cation Affinities } \\
\hline $\mathrm{P} 1$ & & & & & & & & & & & & & $\mathrm{He}$ & 1.0 & -4.4 & -3.5 \\
\hline $\mathrm{P} 2$ & $\mathrm{NH}_{3}$ & 15.7 & -6.2 & 9.5 & $\mathrm{OH}_{2}$ & 13.8 & -5.9 & 7.9 & $\mathrm{FH}$ & 9.5 & -5.1 & 4.4 & $\mathrm{Ne}$ & 0.9 & -4.2 & -3.3 \\
\hline P3 & $\mathrm{PH}_{3}$ & 8.2 & -5.4 & 2.8 & $\mathrm{SH}_{2}$ & 8.0 & -5.1 & 2.8 & $\mathrm{ClH}$ & 5.4 & -4.4 & 1.0 & $\mathrm{Ar}$ & 1.5 & -3.7 & -2.2 \\
\hline P4 & $\mathrm{AsH}_{3}$ & 6.1 & -5.3 & 0.8 & $\mathrm{SeH}_{2}$ & 7.9 & -5.2 & 2.7 & $\mathrm{BrH}$ & 5.3 & -4.4 & 0.9 & $\mathrm{Kr}$ & 2.1 & -3.8 & -1.7 \\
\hline P5 & $\mathrm{SbH}_{3}$ & 4.8 & -5.0 & -0.2 & $\mathrm{TeH}_{2}$ & 8.3 & -4.9 & 3.4 & $\mathrm{IH}$ & 5.8 & -4.2 & 1.6 & $\mathrm{Xe}$ & 2.9 & -3.8 & -0.9 \\
\hline P6 & $\mathrm{BiH}_{3}$ & 1.1 & -4.7 & -3.6 & $\mathrm{PoH}_{2}$ & 8.7 & -5.1 & 3.6 & AtH & 6.1 & -4.4 & 1.7 & $\mathrm{Rn}$ & 3.4 & -3.8 & -0.4 \\
\hline \multicolumn{17}{|c|}{ Cesium Cation Affinities } \\
\hline P1 & & & & & & & & & & & & & $\mathrm{He}$ & 0.9 & -4.3 & -3.4 \\
\hline $\mathrm{P} 2$ & $\mathrm{NH}_{3}$ & 13.7 & -6.0 & 7.6 & $\mathrm{OH}_{2}$ & 12.1 & -5.7 & 6.4 & FH & 8.3 & -5.0 & 3.2 & $\mathrm{Ne}$ & 0.9 & -4.1 & -3.2 \\
\hline P3 & $\mathrm{PH}_{3}$ & 6.8 & -5.1 & 1.7 & $\mathrm{SH}_{2}$ & 6.7 & -4.9 & 1.8 & $\mathrm{ClH}$ & 4.5 & -4.1 & 0.3 & $\mathrm{Ar}$ & 1.1 & -3.3 & -2.2 \\
\hline P4 & $\mathrm{AsH}_{3}$ & 4.9 & -5.1 & -0.1 & $\mathrm{SeH}_{2}$ & 6.6 & -5.0 & 1.6 & $\mathrm{BrH}$ & 4.4 & -4.2 & 0.2 & $\mathrm{Kr}$ & 1.6 & -3.6 & -2.0 \\
\hline P5 & $\mathrm{SbH}_{3}$ & 3.7 & -4.7 & -1.0 & $\mathrm{TeH}_{2}$ & 6.9 & -4.6 & 2.3 & $\mathrm{IH}$ & 4.8 & -4.0 & 0.8 & $\mathrm{Xe}$ & 2.3 & -3.6 & -1.3 \\
\hline P6 & $\mathrm{BiH}_{3}$ & 0.4 & -4.4 & -4.0 & $\mathrm{PoH}_{2}$ & 7.3 & -4.9 & 2.3 & AtH & 5.1 & -4.2 & 0.9 & $\mathrm{Rn}$ & 2.8 & -3.6 & -0.8 \\
\hline
\end{tabular}

${ }^{a}$ Computed at ZORA-BP86/QZ4P//ZORA-BP86/TZ2P for the reaction $\mathrm{MXH}_{n}^{+} \rightarrow \mathrm{M}^{+}+\mathrm{XH}_{n}$ at $298.15 \mathrm{~K}$ and $1 \mathrm{~atm}$.

affinities of our neutral Lewis bases $\mathrm{XH}_{n}$ change along the group- 1 cations $\mathrm{H}^{+}, \mathrm{Li}^{+}, \mathrm{Na}^{+}, \mathrm{K}^{+}, \mathrm{Rb}^{+}$, and $\mathrm{Cs}^{+}$.

\section{METHODS}

2.1. Basis Sets. All calculations were performed with the Amsterdam Density Functional (ADF) program. ${ }^{43,44}$ The numerical integration is performed by using a procedure developed by te Velde et al. ${ }^{45,46}$

Molecular orbitals (MOs) were expanded using two large, uncontracted sets of Slater-type orbitals (STOs): TZ2P for geometry optimization and vibrational analysis and QZ4P for single-point energy calculations. ${ }^{47}$ The TZ2P basis set is of triple- $\zeta$ quality, augmented by two sets of polarization functions ( $\mathrm{d}$ and $\mathrm{f}$ on heavy atoms; $2 \mathrm{p}$ and $3 \mathrm{~d}$ sets on $\mathrm{H}$ ). The QZ4P basis, which contains additional diffuse functions, is of quadruple- $\zeta$ quality, augmented by four sets of polarization functions (two $3 \mathrm{~d}$ and two $4 \mathrm{f}$ sets on $\mathrm{C}, \mathrm{N}$, and $\mathrm{O}$; two $2 \mathrm{p}$ and two $3 \mathrm{~d}$ sets on $\mathrm{H}$ ). Core electrons (e.g., 1s for second-period, $1 \mathrm{~s} 2 \mathrm{~s} 2 \mathrm{p}$ for third-period, $1 \mathrm{~s} 2 \mathrm{~s} 2 \mathrm{p} 3 \mathrm{~s} 3 \mathrm{p}$ for fourth-period, $1 \mathrm{~s} 2 \mathrm{~s} 2 \mathrm{p} 3 \mathrm{~s} 3 \mathrm{p} 3 \mathrm{~d} 4 \mathrm{~s} 4 \mathrm{p}$ for fifth-period, and $1 \mathrm{~s} 2 \mathrm{~s} 2 \mathrm{p} 3 \mathrm{~s} 3 \mathrm{p} 3 \mathrm{~d} 4 \mathrm{~s} 4 \mathrm{p} 4 \mathrm{~d}$ for sixth-period atoms) were treated by the frozen core approximation. ${ }^{47}$ An auxiliary set of s, p, d, f, and g Slater-type orbitals was used to fit the molecular density and to represent the Coulomb and exchange potentials accurately in each selfconsistent field (SCF) cycle.

2.2. Density Functional. Energies and gradients were calculated using the local density approximation (LDA: Slater ${ }^{48}$ exchange and $\mathrm{VWN}^{49}$ correlation) with gradient corrections due to Becke (exchange) and Perdew (correlation) added self-consistently. ${ }^{50-52}$ This is the BP86 density func- 
PA
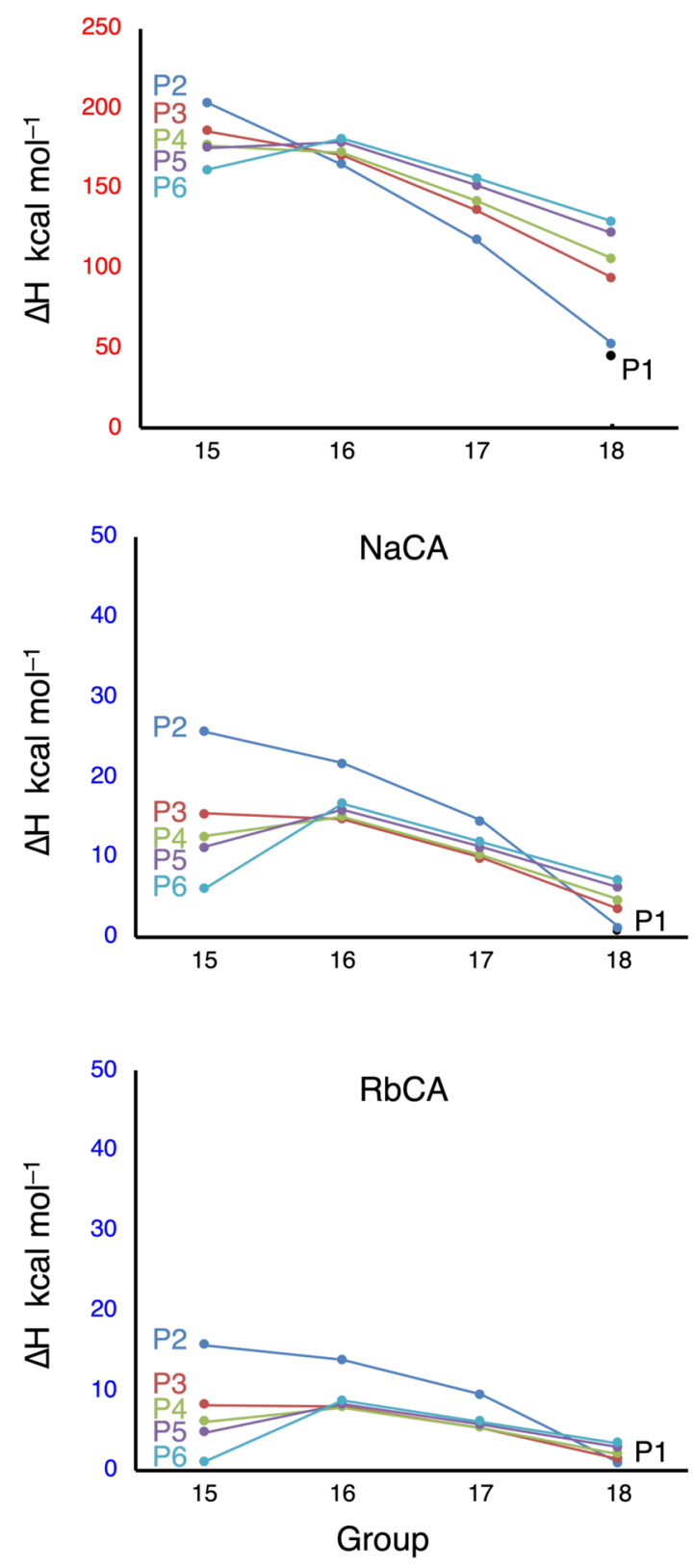

LiCA
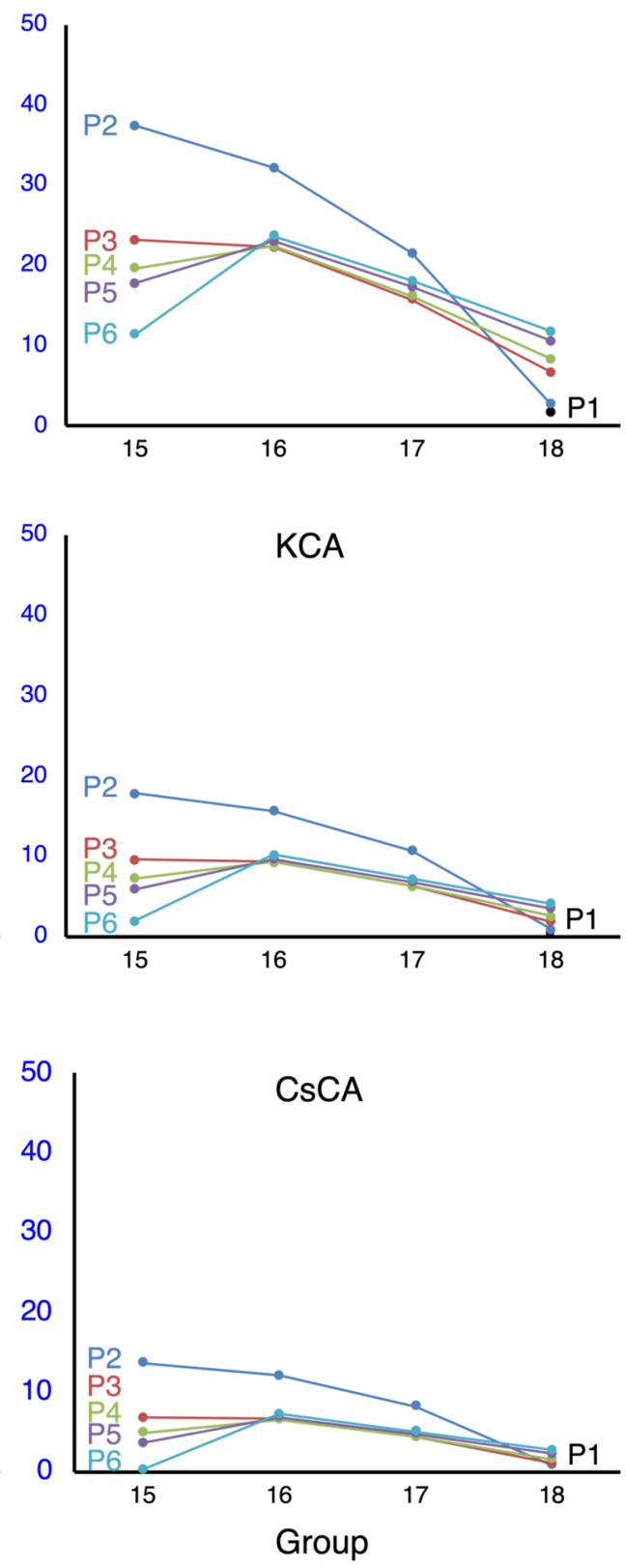

Figure 1. Alkali metal cation affinities AMCAs at $298 \mathrm{~K}$ of the neutral maingroup-element hydrides $\mathrm{XH}_{n}$ of groups 15-18 and periods 1-6 (P1P6) and the corresponding proton affinities PAs, computed at ZORA-BP86/QZ4P//ZORA-BP86/TZ2P.

tional, which is one of the three best DFT functionals for the accuracy of geometries ${ }^{14-16,53}$ with an estimated unsigned error of $0.009 \AA$ in combination with the TZ2P basis set. In a previous study ${ }^{14-16}$ on the proton affinities of anionic species, we compared the energies of a range of other DFT functionals, to estimate the influence of the choice of DFT functional. These functionals included the local density approximation (LDA), generalized gradient approximation (GGA), metaGGA, and hybrid functionals. Scalar relativistic corrections were included self-consistently using the zeroth order regular approximation (ZORA). ${ }^{54}$ Spin-orbit coupling effects were neglected because they are small for closed-shell systems as they occur in this investigation.

Geometries, vibrational frequencies, and thermodynamic corrections have been computed using the TZ2P basis set: ZORA-BP86/TZ2P level. All electronic energies have been computed in a single-point fashion using the QZ4P basis set, based on the ZORA-BP86/TZ2P geometries: ZORA-BP86/ QZ4P//ZORA-BP86/TZ2P. The bonding analyses have been carried out at the ZORA-BP86/TZ2P level of theory. All equilibrium geometries (see the Supporting Information) are verified by vibrational analyses to be (local) minima on the potential energy surface (zero imaginary frequencies).

2.3. Thermochemistry. Enthalpies at $298.15 \mathrm{~K}$ and $1 \mathrm{~atm}$ $\left(\Delta H_{298}\right)$ were calculated from electronic bond energies $(\Delta E)$ at ZORA-BP86/QZ4P//ZORA-BP86/TZ2P and vibrational frequencies at ZORA-BP86/TZ2P using standard thermochemistry relations for an ideal gas, according to eq $3:^{55,56}$

$$
\begin{aligned}
\Delta H_{298}= & \Delta E+\Delta E_{\text {trans }, 298}+\Delta E_{\mathrm{rot}, 298}+\Delta E_{\mathrm{vib}, 0} \\
& +\Delta\left(\Delta E_{\mathrm{vib}, 0}\right)_{298}+\Delta(p V)
\end{aligned}
$$


PA Neutral

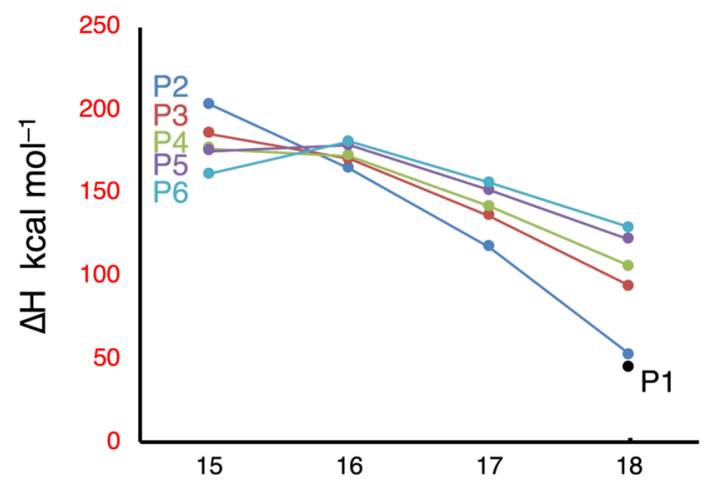

PA Anionic

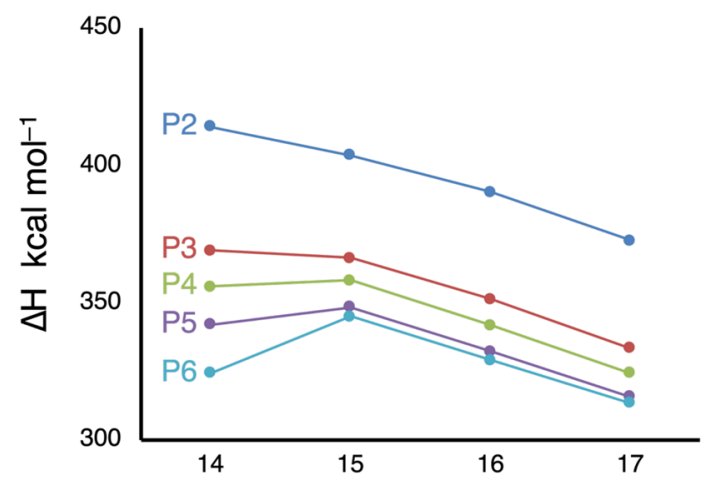

Group
LiCA Neutral

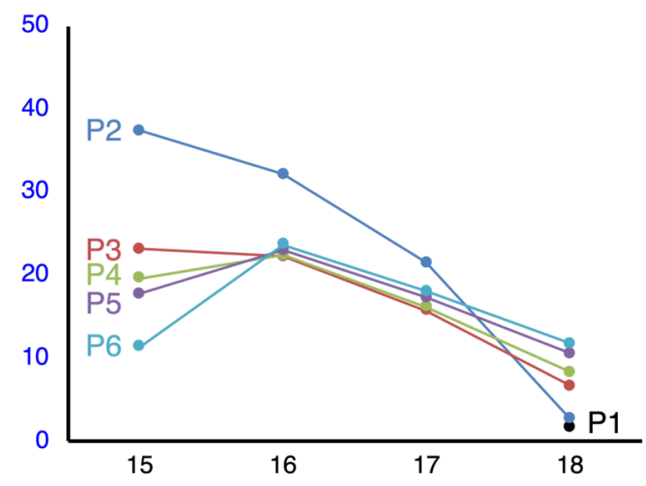

LiCA Anionic

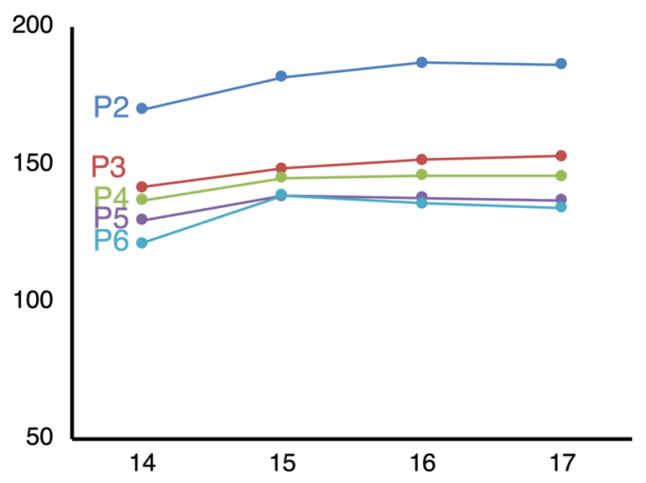

Group

Figure 2. Proton affinities (PAs) and lithium cation affinities (LiCAs) at $298 \mathrm{~K}$ of the neutral $\left(\mathrm{XH}_{n}\right)$ maingroup-element hydrides of groups $15-18$ and periods 1-6 (P1-P6) and the corresponding proton affinities (PAs) and lithium cation affinities of the anionic $\left(\mathrm{XH}_{n-1}{ }^{-}\right)$maingroup-element $^{-}$ hydrides of groups 14-17 and periods 2-6 (P2-P6), computed at ZORA-BP86/QZ4P//ZORA-BP86/TZ2P.

Here, $\Delta E_{\text {trans,298, }} \Delta E_{\text {rot,298, }}$ and $\Delta E_{\text {vib,0 }}$ are the differences between the reactant (i.e., $\mathrm{MXH}_{n}{ }^{+}$, the base-cation complex) and products (i.e., $\mathrm{M}^{+}+\mathrm{XH}_{n}$, the cation and the neutral base) in translational, rotational, and zero-point vibrational energy, respectively. $\Delta\left(\Delta E_{\mathrm{vib}, 0}\right)_{298}$ is the change in the vibrational energy difference as one goes from 0 to $298.15 \mathrm{~K}$. The vibrational energy corrections are based on our frequency calculations. The molar work term $\Delta(p V)$ is $(\Delta n) R T ; \Delta n=+1$ for one reactant $\mathrm{MXH}_{n}^{+}$dissociating into two products $\mathrm{M}^{+}$and $\mathrm{XH}_{n}$. Thermal corrections for the electronic energy are neglected. The change of the Gibbs energy $(\Delta G)$ in the gas phase is calculated for $298.15 \mathrm{~K}$ and 1 atm (eq 4).

$$
\Delta G_{298}=\Delta H_{298}-T \Delta S_{298}
$$

2.4. Bond-Energy Decomposition Analysis. The bonding analyses have been carried out at the ZORA-BP86/ TZ2P level of theory. The overall bond energy $\Delta E_{\text {bond }}$ (which corresponds to $-\Delta E$ in eq 3 ) between cation $\mathrm{M}^{+}$and base $\mathrm{XH}_{n}$ is made up of two major components: ${ }^{57-60}$

$$
\Delta E_{\text {bond }}=\Delta E_{\text {strain }}+\Delta E_{\text {int }}
$$

Here, the strain energy $\Delta E_{\text {strain }}$ is the amount of energy required to deform the separate base from its equilibrium structure to the geometry that they acquire in the overall complex $\mathrm{MXH}_{n}{ }^{+}$. The interaction energy $\Delta E_{\text {int }}$ corresponds to the actual energy change when the geometrically deformed base combines with the cation to form the overall complex.

The interaction $\Delta E_{\text {int }}$ between the deformed reactants is further decomposed into three physically meaningful terms, in the conceptual framework provided by the Kohn-Sham molecular orbital (KS-MO) model (eq 6). ${ }^{43,57-60}$

$$
\Delta E_{\text {int }}=\Delta V_{\text {elstat }}+\Delta E_{\text {Pauli }}+\Delta E_{\text {oi }}
$$

The $\Delta V_{\text {elstat }}$ term corresponds to the classical electrostatic interaction between unperturbed charge distributions $\rho_{\mathrm{A}}(r)+$ $\rho_{\mathrm{B}}(r)$ of the deformed fragments $\mathrm{A}$ and $\mathrm{B}$ and is usually attractive. The Pauli repulsion $\Delta E_{\text {Pauli }}$ comprises the destabilizing interactions between occupied orbitals (more precisely, between same-spin orbitals) and is responsible for any steric repulsion. The orbital interaction $\Delta E_{\mathrm{oi}}$ accounts for electronpair bonding, charge transfer (interaction between occupied orbitals on one fragment with unoccupied orbitals of the other fragment, including HOMO-LUMO interactions), and polarization (empty-occupied orbitals mixing on one fragment due to the presence of another fragment).

\section{RESULTS AND DISCUSSION}

3.1. AMCAs and PAs of Neutral Maingroup-Element Hydrides. Our ZORA-BP86/QZ4P//ZORA-BP86/TZ2P computed alkali metal cation affinities (AMCAs) and proton 
$(-)$ PA
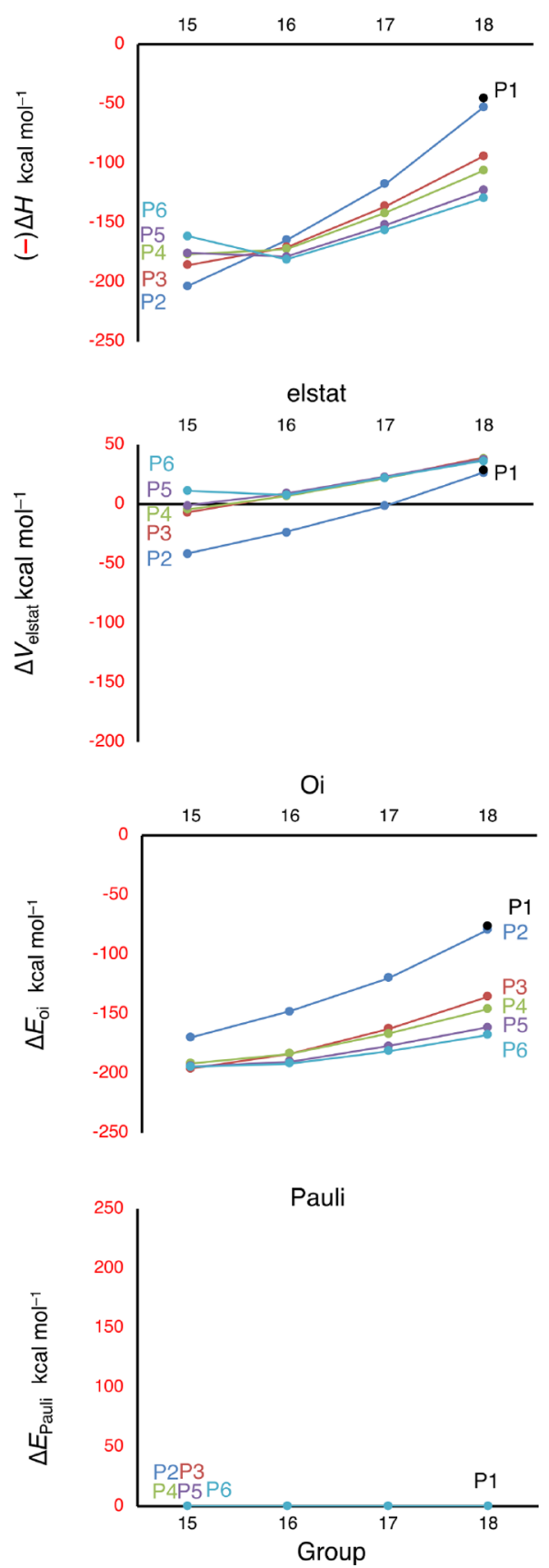

(-) LiCA
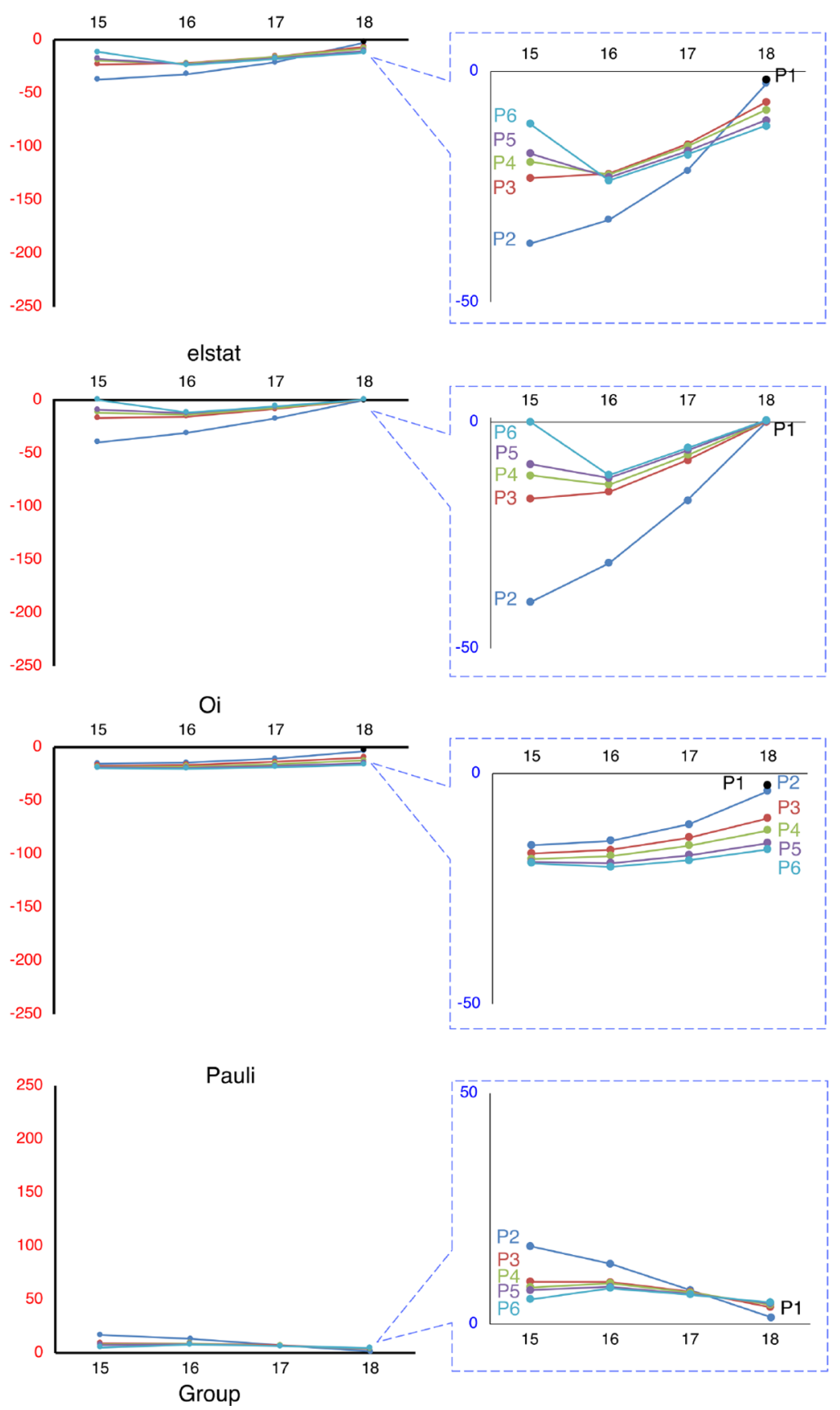

Figure 3. Energy decomposition analysis of proton affinity (PA) and lithium cation affinity (LiCA) energies $\Delta E$ of neutral bases $\mathrm{XH}_{n}$, computed at ZORA-BP86/TZ2P.

affinities (PAs) at $298 \mathrm{~K}(\Delta H)$, the corresponding entropies $\Delta S$ (provided as $-T \Delta S$ values), and free energies $\Delta G$ of all neutral maingroup-element hydrides of group 15-18 and periods $1-6$ are summarized in Table 1 and Figure 1.

The AMCAs, but also the PAs, of the neutral maingroupelement hydrides $\mathrm{XH}_{n}$ are considerably weaker than those of the corresponding anionic Lewis bases $\mathrm{XH}_{n-1}{ }^{-}$. This weakening is due to the fact that dissociation of the complex in the latter is associated with charge separation and thus substantial electrostatic attraction (eq 2), whereas no charge separation occurs in the former (eq 1). Consequently, the AMCAs of the anionic bases benefit from a substantially more stabilizing electrostatic attraction than the neutral bases. This and other features behind AMCA trends are discussed in more detail, later on, in the section on the bonding mechanism.

The trend in AMCA along the various neutral maingroupelement hydrides $\mathrm{XH}_{n}$ shows characteristic patterns which are similar for each of the alkali metal cations (vide infra). Along the alkali metal cations, down group 1, the AMCA of a Lewis base $\mathrm{XH}_{n}$, in general, systematically weakens. Furthermore, the $\mathrm{XH}_{n}$ AMCAs are substantially smaller than the corresponding PAs by about $150-200 \mathrm{kcal} \mathrm{mol}^{-1}$ (see Table 1), similar to our earlier finding for the anionic Lewis bases $\mathrm{XH}_{n-1}-{ }^{41}$ Our bonding analyses reveal that these differences mainly stem from weaker orbital interactions of $\mathrm{XH}_{n}$ with the alkali metal cations as compared to those with the proton (vide infra). 
Gibbs energies $\Delta G_{298}$ show the same trends as the corresponding enthalpic AMCA values (see Table 1). The reason is that the corresponding reaction entropies yield a relatively small and/or little varying contribution $-T \Delta S_{298}$ of -8 to $-3 \mathrm{kcal} \mathrm{mol}^{-1}$ along the entire set of model Lewis bases. Note that the AMCAs of most of the noble gases have negative Gibbs energies associated with their AMCAs. This means that these complexes are thermodynamically not stable and would dissociate spontaneously. For example, whereas $\Delta G_{298}$ for dissociating a sodium cation from radon amounts to $+2.9 \mathrm{kcal}$ $\mathrm{mol}^{-1}$ (i.e., the complex is thermodynamically stable), the corresponding value for helium is $-3.1 \mathrm{kcal} \mathrm{mol}^{-1}$, indicating that dissociation of $\mathrm{HeNa}^{+}$occurs spontaneously (see Table 1).

Along the second and third periods, the AMCA $\left(\mathrm{XH}_{n}\right)$ decreases from group 15 to 18 . A major change occurs in the affinity when one descends down the groups. The neutral AMCAs $\left(\mathrm{XH}_{n}\right)$ show an inversion in the trend down a group going from group 15 to group 18. Thus, descending group 15, the AMCA decreases, but descending group 18, it increases. The same trend in the affinity is also observed in the PAs of the neutral maingroup-element hydrides $\left(\mathrm{XH}_{n}\right)$, while it differs significantly from those previously found for the anionic conjugate bases $\left(\mathrm{XH}_{n-1}^{-}\right)$of the maingroup-element hydrides where the AMCA, as well as $\mathrm{PA}$, of the anionic bases $\left(\mathrm{XH}_{n-1}{ }^{-}\right)$ always decreases down a group.

However, there is an interesting analogy between the AMCA, as well as PA, trends of $\mathrm{XH}_{n}$ and $\mathrm{XH}_{n-1}{ }^{-}$, which can be recognized in Figure 2. For both bases, the kink in the affinity trend along a period occurs after the step from the tricoordinate base (group 15 for $\mathrm{XH}_{n}$ and group 14 for $\mathrm{XH}_{n-1}{ }^{-}$) to the dicoordinate base (group 16 for $\mathrm{XH}_{n}$ and group 15 for $\mathrm{XH}_{n-1}{ }^{-}$). This kink is more pronounced for bases with a heavier protophilic center, that is, as we go from the third period down to the sixth period. In a previous study on proton affinities, ${ }^{14-16}$ this phenomenon has been ascribed to the valence $n$ s electrons on the protophilic center " $\mathrm{X}$ " of the base becoming increasingly inactive down a period because of the relativistic stabilization of the $n$ s AO. The sudden increase in cation affinity from a trivalent to a bivalent base is associated with an active np-type lone pair (which is always at higher energy than the $n$ s electron pair) becoming available in the latter.

3.2. Bonding Mechanism: Variation of the Neutral Base. Our heterolytic $\left(\mathrm{M}^{+}\right)-\left(\mathrm{XH}_{n}\right)$ bonding analyses have been carried out at ZORA-BP86/TZ2P and comprise two complementary approaches: (i) quantitative analysis of the Kohn-Sham orbital interaction mechanism and (ii) the associated bond energy decomposition (see Figure 3). In the discussion, we focus on the lithium cation affinity (LiCA) due to the similarity in trends between this cation and the rest of the alkali metal cations. Furthermore, we compare this LiCA of the neutral bases $\mathrm{XH}_{n}$ with the corresponding PA and with the AMCAs of the anionic maingroup-element hydrides $\left(\mathrm{XH}_{n-1}^{-}\right)$. Detailed numerical results from the analyses of all alkali metal cation (AMCA) as well as proton (PA) affinities can be found in the Supporting Information (see Tables S1-S6).

The trend in cation affinity $\Delta H$ is determined by that in the electronic cation affinity energy $\Delta E$ associated with reaction 1 . Note that, for the bonding analysis, we use the bond energy $\Delta E_{\text {bond }}=-\Delta E$, that is, the energy change associated with bond formation $\mathrm{M}^{+}+\mathrm{XH}_{n} \rightarrow \mathrm{MXH}_{n}^{+}$. The main contributor to $\Delta E_{\text {bond }}=\Delta E_{\text {strain }}+\Delta E_{\text {int }}$ in turn, is the interaction energy
$\Delta E_{\text {int }}$ between the two fragments which determines the overall trend in stability. $\Delta E_{\text {bond }}$ follows the same trend as $\Delta E_{\text {int }}$ because the relatively small strain energy $\Delta E_{\text {strain }}$ does not affect this trend in interaction. The reason is that, for $n=0-2$, the bases $\mathrm{XH}_{n}$ do not have to deform much when forming the complex with the cation. An exception is constituted by the three-coordinate bases $\mathrm{XH}_{n}$ of group 15 which are sterically more crowded and undergo a slight, yet significant change in pyramidality as they bind to the cation. ${ }^{61}$ The $\Delta E_{\text {strain }}$ values in this group are in the order of $18 \mathrm{kcal} \mathrm{mol}^{-1}$ for PAs and $2 \mathrm{kcal}$ $\mathrm{mol}^{-1}$ for LiCAs. This significant decrease in the $\Delta E_{\text {strain }}$ values going from the proton to the lithium cation can be ascribed to the weaker $\mathrm{X}-\mathrm{Li}$ interaction which affects the $\mathrm{XH}_{3}$ fragment to a lesser extent. In any case, as stated before, this strain effect is too small to change the overall trend in relative stability that is set by $\Delta E_{\text {int }}$. A similar situation was previously found for the anionic conjugate bases $\left(\mathrm{XH}_{3}^{-}\right)$of the maingroup-element hydrides of group $14 .^{41}$

The interaction $\Delta E_{\text {int }}$ behind the cation affinities originates from a combination of three phenomena in the bonding mechanism: (i) electrostatic attraction $\Delta V_{\text {elstat }}$ which is weak for neutral $\mathrm{XH}_{n}$, as compared to the situation of the anionic $\mathrm{XH}_{n}$, due to the absence of charge separation in the former; (ii) orbital interaction $\Delta E_{\mathrm{oi}}$ which is significantly stronger for $\mathrm{H}^{+}$than $\mathrm{Li}^{+}$; and (iii) Pauli repulsion with the core AOs of the alkali cations which lessens all AMCAs and thus also the lithium cation affinity (LiCA), whereas no Pauli repulsion occurs in the PAs, as the proton has no core electrons. We recall that the AMCAs of the heavier alkali cations behave similarly to those of the lithium cation, with the understanding that they are even further weakened with respect to the corresponding PAs.

The electrostatic attraction $\Delta V_{\text {elstat }}$ of the neutral bases $\mathrm{XH}_{n}$ is relatively weak toward both lithium cations and protons if compared to the situation of the anionic bases $\mathrm{XH}_{n-1}{ }^{-}$in which case a strong Coulomb attraction between oppositely charged fragments occurs. This is the main difference between the cation affinities of the neutral and anionic Lewis bases. ${ }^{41}$ The exact trend in electrostatic interaction depends in an intricate manner on the shape and mutual penetration of the fragment charge distributions. ${ }^{62-64}$ Therefore, significant deviations of Coulomb's law $q_{1} \cdot q_{2} / r_{12}$ for two point charges occur. Still, one can observe a weakening in the values of $\Delta V_{\text {elstat }}$ as the equilibrium bond length increases down the groups. This weakening of the AMCA down a group is also computed for the values of the electrostatic attraction of the other alkali metal cations. Likewise, essentially the same trend of a weakening in $\Delta V_{\text {elstat }}$ occurs if the cation itself varies down group 1, i.e., along $\mathrm{M}^{+}=\mathrm{Li}^{+}, \mathrm{Na}^{+}, \mathrm{K}^{+}, \mathrm{Rb}^{+}$, and $\mathrm{Cs}^{+}$(see Tables S2-S6 in the Supporting Information).

As mentioned above, for the PA, the orbital interaction $\Delta E_{\mathrm{oi}}$ becomes the dominant component in the interaction going from anionic $\left(\mathrm{XH}_{n-1}^{-}\right)$to neutral $\left(\mathrm{XH}_{n}\right)$ bases of the maingroup-element hydrides. For both cases, anionic as well as neutral bases, it is the main responsible interaction term causing the weakening in the affinity going from PA to LiCA. As can be seen in Figure 3, the orbital interaction $\Delta E_{\mathrm{oi}}$ of the lithium cation is about $150 \mathrm{kcal} \mathrm{mol}^{-1}$ weaker than the corresponding one of the proton. This strong weakening in $\Delta E_{\mathrm{oi}}$, going from $\mathrm{H}^{+}$to $\mathrm{Li}^{+}$, is caused by the increase in the HOMO-LUMO gap (the energy of the LUMO increases drastically as one goes from the proton $-13.6 \mathrm{eV}$ to the lithium metal cation $-6.9 \mathrm{eV}$ ) and the decrease in the HOMO- 


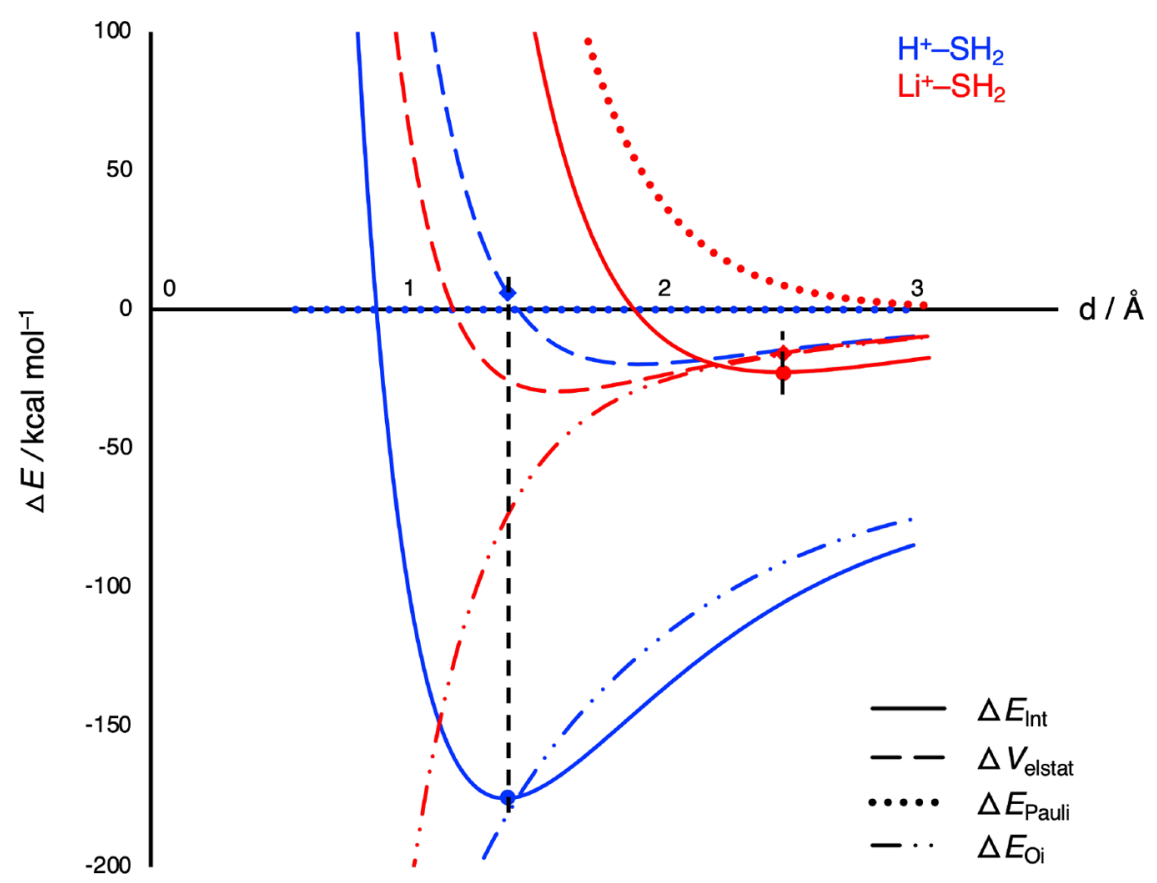

Figure 4. Energy decomposition analysis of the $\mathrm{H}^{+}-\mathrm{SH}_{2}$ and $\mathrm{Li}^{+}-\mathrm{SH}_{2}$ interaction $\Delta E_{\text {int }}$ as a function of the bond distance $d$, computed at $\mathrm{ZORA}$ BP86/TZ2P.
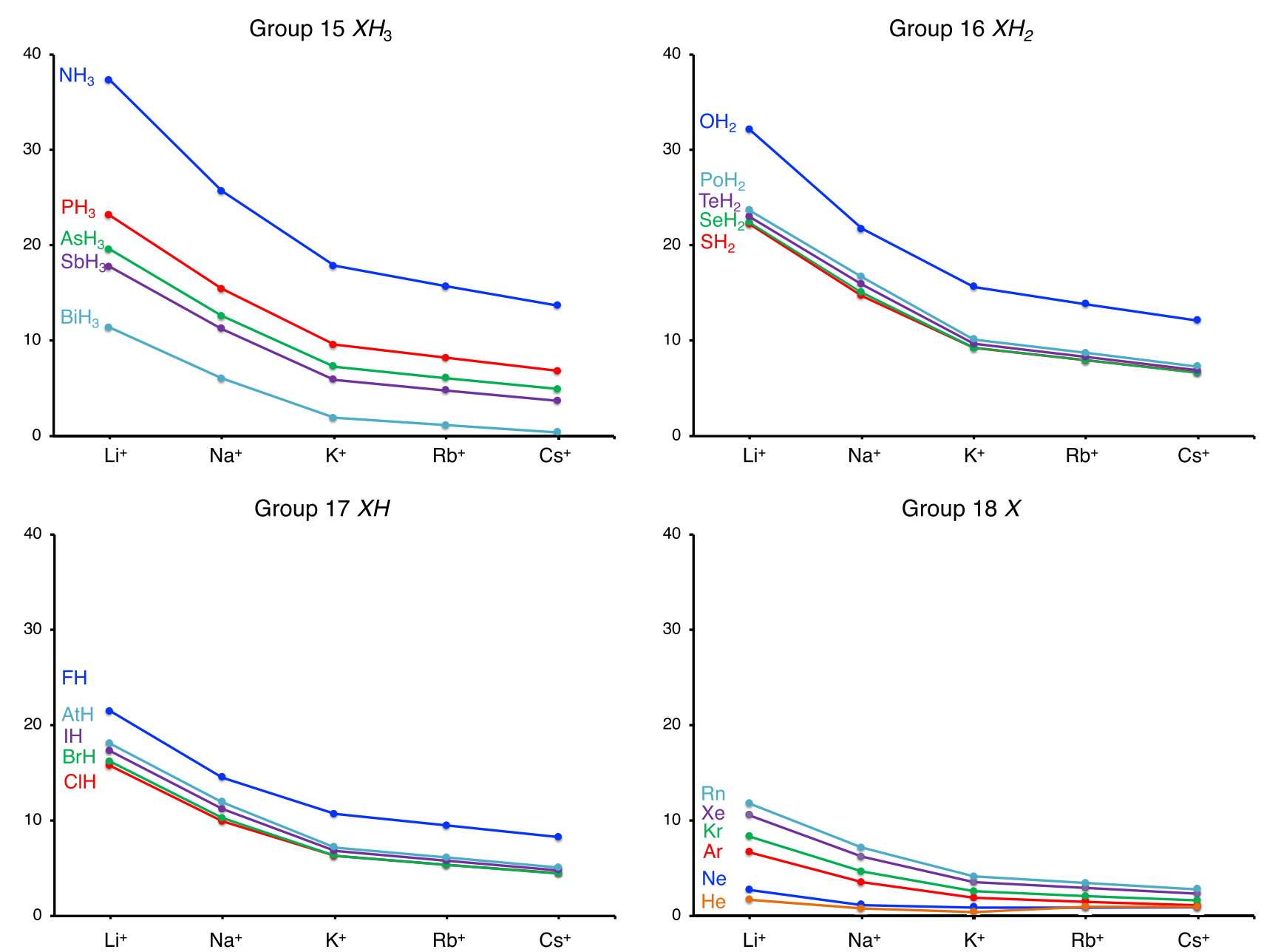

Figure 5. Alkali metal cation affinities (AMCAs) at $298 \mathrm{~K}$ of neutral maingroup-element hydrides of groups $15,16,17$, and $18\left(\mathrm{XH}_{3}, \mathrm{XH}_{2}, \mathrm{XH}^{\mathrm{X}}\right)$ and periods 1-6 (P1-P6), as a function of the cation, computed at ZORA-BP86/QZ4P//ZORA-BP86/TZ2P. 
Table 2. Linear Correlation Function of AMCA with PA and of AMCA with LICA Values (in kcal mol ${ }^{-1}$ ) for Anionic and Neutral Maingroup-Element Hydrides, Together with the Correlation Coefficient $r^{2}$ and Standard Deviation SD ${ }^{a}$

\begin{tabular}{|c|c|c|c|c|c|}
\hline AMCA vs PA & $r^{2}$ & SD & AMCA vs LiCA & $r^{2}$ & SD \\
\hline \multicolumn{6}{|c|}{ Anionic Bases $\left(\mathrm{XH}_{n-1}^{-}\right)$} \\
\hline $\mathrm{LiCA}=0.517 \mathrm{PA}-33.597$ & 0.597 & 12.2 & & & \\
\hline $\mathrm{NaCA}=0.410 \mathrm{PA}-13.255$ & 0.710 & 7.5 & $\mathrm{NaCA}=0.718 \mathrm{LiCA}+24.335$ & 0.976 & 2.1 \\
\hline $\mathrm{KCA}=0.377 \mathrm{PA}-18.855$ & 0.552 & 9.7 & $\mathrm{KCA}=0.757 \mathrm{LiCA}+1.532$ & 0.996 & 0.9 \\
\hline $\mathrm{RbCA}=0.368 \mathrm{PA}-19.841$ & 0.541 & 9.7 & $\mathrm{RbCA}=0.746 \mathrm{LiCA}-0.965$ & 0.995 & 1.0 \\
\hline $\mathrm{CsCA}=0.377 \mathrm{PA}-26.389$ & 0.495 & 10.9 & $\mathrm{CsCA}=0.795 \mathrm{LiCA}-11.815$ & 0.989 & 1.6 \\
\hline \multicolumn{6}{|c|}{ Neutral Bases $\left(\mathrm{XH}_{n}\right)$} \\
\hline $\mathrm{LiCA}=0.177 \mathrm{PA}-8.107$ & 0.712 & 4.9 & & & \\
\hline $\mathrm{NaCA}=0.125 \mathrm{PA}-6.667$ & 0.683 & 3.7 & $\mathrm{NaCA}=0.719 \mathrm{LiCA}-1.179$ & 0.996 & 0.4 \\
\hline $\mathrm{KCA}=0.079 \mathrm{PA}-4.274$ & 0.531 & 3.2 & $\mathrm{KCA}=0.505 \mathrm{LiCA}-1.718$ & 0.964 & 0.9 \\
\hline $\mathrm{RbCA}=0.066 \mathrm{PA}-3.427$ & 0.480 & 3.0 & $\mathrm{RbCA}=0.440 \mathrm{LiCA}-1.581$ & 0.942 & 1.0 \\
\hline $\mathrm{CsCA}=0.055 \mathrm{PA}-2.842$ & 0.431 & 2.7 & $\mathrm{CsCA}=0.382 \mathrm{LiCA}-1.563$ & 0.916 & 1.0 \\
\hline
\end{tabular}

${ }^{a}$ Computed at ZORA-BP86/QZ4P//ZORA-BP86/TZ2P at $298.15 \mathrm{~K}$ and $1 \mathrm{~atm}$. See Figure 6 for graphical representations of the correlated values.

LUMO bond overlap as a result of the diffuse nature of the alkali metal cation $n$ s LUMOs (see also ref 42). However, both $\mathrm{H}^{+}$and $\mathrm{Li}^{+}$show a common trend in the orbital interaction. The orbital interaction becomes in general less stabilizing along a period and more stabilizing down a group.

This is a direct result of the trend in lone-pair orbital energies of the neutral bases $\mathrm{XH}_{n}$ of the maingroup-element hydrides. Along the periods, the lone-pair orbitals of the protophilic atom become more compact and stable: -6.3 , $-9.4,-13.6$, to $-13.6 \mathrm{eV}$ for $\mathrm{NH}_{3}, \mathrm{OH}_{2}, \mathrm{FH}$, and $\mathrm{Ne}$, respectively. On the contrary, down the groups, these HOMO orbitals become less stable and go up in energy, especially down group 18, as the principal quantum number increases from $n=1$ until $n=6$ : $-15.6,-13.6,-10.3,-9.3,-8.3$, and $-7.8 \mathrm{eV}$ along $\mathrm{He}, \mathrm{Ne}, \mathrm{Ar}, \mathrm{Kr}, \mathrm{Xe}$, and $\mathrm{Rn}$, respectively. On the other hand, down group 15, the orbital energies of the bases change relatively little: $-6.3,-6.9,-7.0,-6.7$, to $-6.9 \mathrm{eV}$ along $\mathrm{NH}_{3}, \mathrm{PH}_{3}, \mathrm{AsH}_{3}, \mathrm{SbH}_{3}$, and $\mathrm{BiH}_{3}$, respectively. This phenomenon causes directly the inversion in the trends where the affinity decreases down the group 15 and it increases down group 18 .

Furthermore, the orbital interaction $\Delta E_{\mathrm{oi}}$ of the neutral maingroup-element hydrides $\mathrm{XH}_{n}$ with either $\mathrm{H}^{+}$or $\mathrm{Li}^{+}$(see Tables S1 and S2) is weaker than that of the corresponding anionic bases $\mathrm{XH}_{n-1}{ }^{-41}$. The reason is that the latter, i.e., $\mathrm{XH}_{n-1}{ }^{-}$, have higher-energy orbitals due to the net negative electrostatic potential that the electrons experience.

A characteristic of the proton-base complexes is that the electrostatic interaction becomes repulsive. The reason is the absence of the repulsive Pauli term in the interactions with a proton. In general, around the equilibrium distance, this Pauli repulsion is the main counteracting term against the attractive $\Delta V_{\text {elstat }}$ and $\Delta E_{\text {oi }}$ components in the bonding mechanism. ${ }^{63,64}$ Its absence in the case of complexes with protons leads to a shorter equilibrium $\mathrm{H}-[\mathrm{X}]^{+}$bond length. At these short distances, $\Delta V_{\text {elstat }}$ becomes repulsive due to the nuclear repulsion which starts to overtake and dominates all other terms in $\Delta V_{\text {elstat }}$ and prevents the bond distance from becoming 0 (see Figure 4). ${ }^{57}$

3.3. Variation of the Alkali Metal Cations. The AMCAs of the neutral bases $\mathrm{XH}_{n}$ decrease down the alkali group (see Figure 5), similar to the previously studied AMCA of the anionic bases $\left(\mathrm{XH}_{n-1}{ }^{-}\right){ }^{41}$ This decrease is caused by a combination of two electronic mechanisms. First, the involvement of the low-lying $2 \mathrm{p}$ AO of the lithium cation in the bonding contributes an extra stabilization, compared to sodium and heavier alkali cations. The reason is that, down group 1 , the valence $n \mathrm{p} \mathrm{AO}$ goes up in energy (from -4.9 to -4.2 to -3.7 to -3.6 to $-3.3 \mathrm{eV}$ along $\mathrm{Li}^{+}, \mathrm{Na}^{+}, \mathrm{K}^{+}, \mathrm{Rb}^{+}$, and $\left.\mathrm{Cs}^{+}\right)$. Consequently, the HOMO-LUMO gap with the base increases and the associated stabilization becomes unimportant.

Second, the weakening in the AMCAs down the alkali cation group, that is, from $\mathrm{Na}^{+}$to $\mathrm{Cs}^{+}$, is mainly caused by the increase in the HOMO-LUMO gap associated with the increase in energy of the alkali cation $n$ s acceptor $\mathrm{AO}$ from $-7.1 \mathrm{eV}\left(\mathrm{Na}^{+}\right)$to $-6.0 \mathrm{eV}\left(\mathrm{K}^{+}\right)$to $-5.9 \mathrm{eV}\left(\mathrm{Rb}^{+}\right)$to $-5.5 \mathrm{eV}$ $\left(\mathrm{Cs}^{+}\right)$. This translates into less stabilization coming from the associated orbital interaction. Furthermore, the HOMOLUMO bond overlap decreases because the alkali cation valence $n \mathrm{~s} \mathrm{AO}$ becomes slightly more diffuse down this alkali cation group. For example, the overlap values between alkali metal cation $n$ s and $\mathrm{NH}_{3} 2 a_{1}$ at their equilibrium distances amount to $0.286,0.251,0.196,0.181$, and 0.166 for $\mathrm{Li}^{+}, \mathrm{Na}^{+}$, $\mathrm{K}^{+}, \mathrm{Rb}^{+}$, and $\mathrm{Cs}^{+}$, respectively (overlap values not shown in a table). This order in overlap values is also found if we take consistently the same $\mathrm{M}-\mathrm{NH}_{3}$ distance for all $\mathrm{M}$. Thus, if we chose, for example, an $\mathrm{M}-\mathrm{N}$ distance of $2.75 \AA$ (i.e., the equilibrium distance in the case of $\mathrm{M}=\mathrm{K}$ ), these overlap values still decrease as $0.213,0.206,0.196,0.186$, and 0.165 along $\mathrm{Li}^{+}, \mathrm{Na}^{+}, \mathrm{K}^{+}, \mathrm{Rb}^{+}$, and $\mathrm{Cs}^{+}$, respectively. Both trends, in the HOMO-LUMO gap and bond overlap, agree with earlier findings of Geerlings et al., who interpreted them in terms of the hardness of the Lewis acids and bases. ${ }^{65-67}$ We recall that the cation affinity increases down group 18 for all alkali metal cations. Note that, in absolute terms, this increase is lighter for the heavier alkali metal cations (see Figure 5). The reason for the smaller variation in cation affinity in the latter case is simply the aforementioned weaker overall affinity, originating from the higher-energy LUMO and thus larger HOMOLUMO gap, of the heavier alkali cations.

Interestingly, down group 1 , the alkali cation $n \mathrm{~d}$ AOs rapidly descend in energy, especially from sodium $(3.8 \mathrm{eV})$ to potassium $(-3.7 \mathrm{eV})$, and begin to play the role of valence orbitals that can accept charge in donor-acceptor interactions. In that capacity, they participate as acceptor orbitals in the HOMO-LUMO interaction with the base instead of the $n \mathrm{~s}$ and $n \mathrm{p}$ AOs. Our finding of a reduced role for the $6 \mathrm{~s}$ and $6 \mathrm{p}$ 

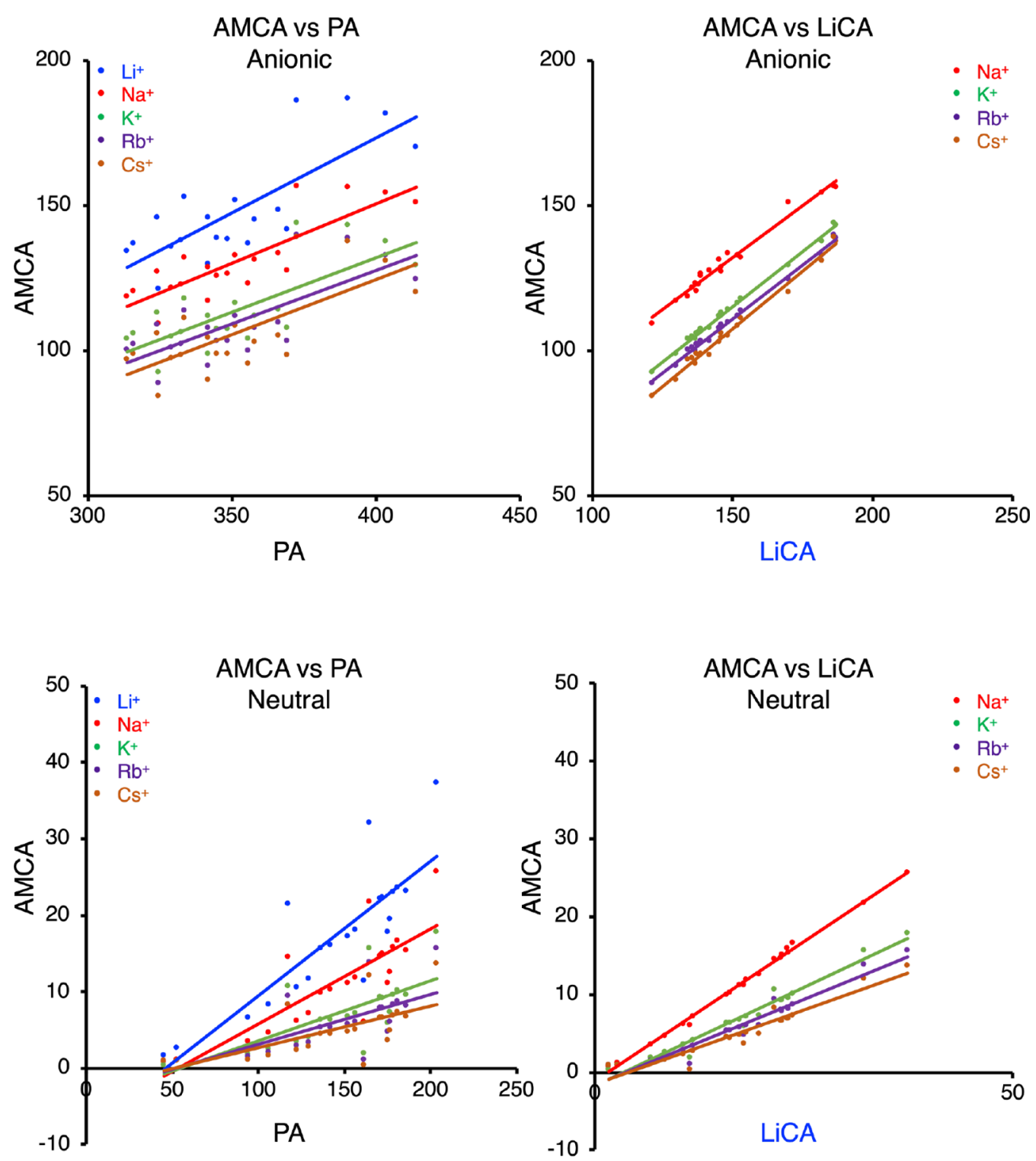

Figure 6. Correlation of alkali metal cation affinities (AMCAs) with proton affinities (PAs) and lithium metal cation affinities (LiCAs), computed at ZORA-BP86/QZ4P//ZORA-BP86/TZ2P (all values in $\mathrm{kcal} \mathrm{mol}^{-1}$; see Table 2).

AOs and an enhanced role of the $6 \mathrm{~d}$ AOs is in line with and augments the recent finding of Goesten et al. ${ }^{68,69}$ that the $6 \mathrm{~s}$ $\mathrm{AO}$ has a significantly reduced importance as a valence orbital for the cesium cation in $\mathrm{CsO}_{4}{ }^{+}$.

3.4. Correlation of the PAs and AMCAs. The linear functions for AMCA-PA and AMCA-LiCA correlations have been summarized in Table 2. Also, the correlation coefficient $\left(r^{2}\right)$ and standard deviation (SD) have been provided for each correlation function with 20 data points for each alkali metal with the anionic bases and 21 data points with the corresponding neutral bases. The correlation coefficient values show, on the one hand, that there is a poor correlation between AMCAs and PAs of the anionic as well as of the corresponding neutral maingroup-element hydrides. The correlation coefficients are between 0.431 and 0.712 with relatively high standard deviations which vary from 2.7 to $12.2 \mathrm{kcal} \mathrm{mol}^{-1}$, which are between 1.4 and $6.5 \%$ of the maximum cation affinity values. This poor correlation is due to the differences in the bonding mechanism between the proton and the alkali metal cations with the conjugate Lewis bases, which is essentially derived from the difference in the orbital interaction. On the other hand, we find a satisfactory correlation between the anionic as well as neutral computed AMCA and the corresponding LiCA values with higher correlation coefficients between 0.916 and 0.996 with relatively low standard deviations which vary from 0.4 to $2.1 \mathrm{kcal} \mathrm{mol}^{-1}$, which are between 0.3 and $1.3 \%$ of the maximum cation affinity values, as can be seen in Figure 6 and Table 2. The better quality of the latter correlation is attributed to the fact that the nature of the bonding mechanism is more similar among all AMCAs than between AMCAs and PAs. This agrees well with previous studies which also reported a good correlation between AMCAs and LiCAs. ${ }^{37,40,70,71}$

\section{CONCLUSIONS}

Alkali metal cation affinities (AMCAs) of neutral maingroupelement hydrides $\mathrm{XH}_{n}$ in the gas phase are significantly smaller than the corresponding proton affinities (PAs) and the AMCAs of the anionic maingroup-element hydrides $\mathrm{XH}_{n-1}{ }^{-}$. These AMCAs show similar trends as the corresponding PAs, 
as the Lewis-basic center $\mathrm{X}$ varies across the periodic table. Furthermore, AMCA values decrease along $\mathrm{Li}^{+}, \mathrm{Na}^{+}, \mathrm{K}^{+}, \mathrm{Rb}^{+}$, and $\mathrm{Cs}^{+}$. This follows from our quantum chemical analyses using relativistic density functional theory at ZORA-BP86/ QZ4P//ZORA-BP86/TZ2P.

The alkali metal cation affinity and the proton affinity decrease along neutral second-period maingroup-element hydrides $\mathrm{NH}_{3}, \mathrm{OH}_{2}, \mathrm{FH}$, and $\mathrm{Ne}$ as valence $2 \mathrm{p}$ AOs of the protophilic atom become more compact and stable. This trend changes down the periodic table, that is, for the higher periods. The AMCA and PA of the maingroup-element hydrides $\mathrm{XH}_{n}$ decrease down group 15, while they increase down group 18. This is due to the more significant decrease of the HOMOLUMO gap and, thus, the more significant stabilization in orbital interactions down group 18 than down group 15, in combination with the fact that the electrostatic attraction weakens in all cases down the periodic table as bond distances become longer. Thus, in the case of group 18, the significant enhancement of the orbital interactions overrules the weakening in electrostatic attraction and causes an overall increase in cation affinity. On the other hand, the trend in orbital interactions is too weak to overcome the weakening in electrostatic attraction down group 15, which results in the aforementioned decrease in affinity.

The AMCA and PA of neutral maingroup-element hydrides $\mathrm{XH}_{n}$ are weaker than the corresponding ones of the anionic maingroup-element hydrides $\mathrm{XH}_{n-1}{ }^{-}$, mainly, because the former go without whereas the latter go with charge separation upon dissociation. Furthermore, weaker orbital interactions and the presence of Pauli repulsion in alkali metal cation complexes are the main factors behind the fact that all AMCAs are weaker than the corresponding PAs.

The various AMCAs show similar trends with respect to variation in the bases. However, the AMCAs become smaller as the alkali cation varies down group 1 because, as the principal quantum number increases from $n=2$ until 6 , the alkali cation $n$ s LUMO goes up in energy and becomes more diffuse, which leads to a weaker and longer bond toward the base. The similarity in bonding mechanisms among the AMCAs is reflected by excellent linear correlations between AMCA and LiCA. This linear relationship may be employed for accurate estimates of AMCAs based on quantum chemical data that need to be computed only for the LiCAs.

\section{ASSOCIATED CONTENT}

\section{S Supporting Information}

The Supporting Information is available free of charge on the ACS Publications website at DOI: 10.1021/acs.jpca.9b03814.

Energy decomposition analysis (EDA) of proton, lithium, sodium, potassium, rubidium, and cesium cation affinities and Cartesian coordinates, total energies $E$, and number of imaginary frequencies NIMAG of all equilibrium structures (PDF)

\section{AUTHOR INFORMATION}

\section{Corresponding Author}

*E-mail: F.M.Bickelhaupt@vu.nl.

\section{ORCID}

Célia Fonseca Guerra: 0000-0002-2973-5321

F. Matthias Bickelhaupt: 0000-0003-4655-7747

Notes

The authors declare no competing financial interest.

\section{ACKNOWLEDGMENTS}

We thank The Netherlands Organization for Scientific Research (NWO) for financial support.

\section{REFERENCES}

(1) Greenwood, N. N.; Earnshaw, A. Chemistry of the Elements, 2nd ed.; Butterworth-Heinemann: Oxford, U.K., 2001.

(2) Cotton, F. A.; Wilkinson, G.; Murillo, C. A.; Bochmann, M. Advanced Inorganic Chemistry, 6th ed.; John Wiley and Sons: New York, 1999.

(3) Verspohl, E. J. Lithium in Biology and Medicine; VCH Verlagsgesellschaft mbH: Weinheim, Germany, 1991.

(4) Fresenius, C. R.; Johnson, S. W. Manual of Qualitative Chemical Analysis; John Wiley and Sons: New York, 1884.

(5) Petrucci, R. H.; Harwood, W. S.; Herring, G. E.; Madura, J. General Chemistry: Principles and Modern Applications, 9th ed.; Pearson-Prentice Hall: Upper Saddle River, NJ, 2006.

(6) Tarascon, J. M.; Armand, M. Issues and Challenges Facing Rechargeable Lithium Batteries. Nature 2001, 414, 359-367.

(7) Dye, J. L. The Alkali Metals: 200 Years of Surprises. Philos. Trans. R. Soc., A 2015, 373, 174-187.

(8) Stoddart, A. Alkali Metal Batteries: Preventing Failure. Nat. Rev. Mater. 2018, 3, 18021.

(9) Zhang, X.; Wang, X. G.; Xie, Z.; Zhou, Z. Recent Progress in Rechargeable Alkali Metal-Air Batteries. Green Energy Environ 2016, 1, 4-17.

(10) Smith, M. B.; March, J. March's Advanced Organic Chemistry: Reactions, Mechanisms, and Structure, 6th ed; John Wiley \& Sons, Inc: Hoboken, NJ, 2013.

(11) Wade, L. G., Jr. Organic Chemistry, 6th ed.; Pearson-Prentice Hall: Upper Saddle River, NJ, 2005.

(12) Clayden, J.; Greeves, N.; Warren, S. Organic Chemistry, 2nd ed.; Oxford University Press: Oxford, U.K., 2012.

(13) Laloo, J. Z.; Rhyman, L.; Ramasami, P.; Bickelhaupt, F. M.; de Cozar, A. Chem. - Eur. J. 2016, 22, 4431-4439.

(14) Swart, M.; Bickelhaupt, F. M. Proton Affinities of Anionic Bases: Trends across the Periodic Table, Structural Effects, and DFT Validation. J. Chem. Theory Comput. 2006, 2, 281-287.

(15) Swart, M.; Rösler, E.; Bickelhaupt, F. M. Proton Affinities of Maingroup-Element Hydrides and Noble Gases: Trends across the Periodic Table, Structural Effects, and DFT Validation. J. Comput. Chem. 2006, 27, 1486-1493.

(16) Swart, M.; Rösler, E.; Bickelhaupt, F. M. Proton Affinities in Water of Maingroup-Element Hydrides - Effects of Hydration and Methyl Substitution. Eur. J. Inorg. Chem. 2007, 23, 3646-3654.

(17) Moser, A.; Range, K.; York, D. M. Accurate Proton Affinity and Gas-Phase Basicity Values for Molecules Important in Biocatalysis. J. Phys. Chem. B 2010, 114, 13911-13921.

(18) Reed, J. L. Electronegativity: Proton Affinity. J. Phys. Chem. 1994, 98, 10477-10483.

(19) Kolboe, S. Proton Affinity Calculations with High Level Methods. J. Chem. Theory Comput. 2014, 10, 3123-3128.

(20) Russo, N.; Toscano, M.; Grand, A. Bond Energies and Attachments Sites of Sodium and Potassium Cations to DNA and RNA Nucleic Acid Bases in the Gas Phase. J. Am. Chem. Soc. 2001, 123, 10272-10279.

(21) Lau, J. K. C.; Wong, C. H. S.; Ng, P. S.; Siu, F. M.; Ma, N. L.; Tsang, C. W. Absolute Potassium Cation Affinities (PCAs) in the Gas Phase. Chem. - Eur. J. 2003, 9, 3383-3396.

(22) Petrie, S. An Improved Theoretical Sodium Cation Affinity Scale? J. Phys. Chem. A 2001, 105, 9931-9938.

(23) Del Bene, J. E. Basis Set and Correlation Effects on Computed Lithium Ion Affinities. J. Phys. Chem. 1996, 100, 6284-6287.

(24) Magnusson, E. Binding of Polar Molecules to $\mathrm{Li}^{+}, \mathrm{Na}^{+}, \mathrm{K}^{+}$, $\mathrm{Mg}^{2+}$, and $\mathrm{Ca}^{2+}$ in Single-Ligand Adducts. J. Phys. Chem. 1994, 98, 12558-12569. 
(25) Valadbeigi, Y. CBS-Q and DFT Calculations of Lithium and Sodium Cations Affinities and Basicities of 60 Organic Molecules. Comput. Theor. Chem. 2016, 1091, 169-175.

(26) Burk, P.; Tammiku-Taul, J.; Tamp, S.; Sikk, L.; Sillar, K.; Mayeux, C.; Gal, J.-F.; Maria, P.-C. Computational Study of Cesium Cation Interactions with Neutral and Anionic Compounds Related to Soil Organic Matter. J. Phys. Chem. A 2009, 113, 10734-10744.

(27) Mayeux, C.; Burk, P. Evaluation of Alkali Metal Cation Affinities and Basicities Using Extrapolation to the Complete Basis Set Limit. J. Phys. Chem. A 2014, 118, 1906-1917.

(28) Kollman, P.; Rothenberg, S. Theoretical Studies of Basicity. Proton Affinities, Lithium(1+) Ion Affinities, and Hydrogen-Bond Affinities of Some Simple Bases. J. Am. Chem. Soc. 1977, 99, 13331342.

(29) Kollman, P. Theoretical Studies of the $\mathrm{K}^{+}$Affinities of Bases: A Comparison of $\mathrm{K}^{+}$and $\mathrm{Li}^{+}$Affinities. Chem. Phys. Lett. 1978, 55, 555559.

(30) Rodgers, M. T.; Armentrout, P. B. Cationic Noncovalent Interactions: Energetics and Periodic Trends. Chem. Rev. 2016, 116, 5642-5687.

(31) Gal, J. F.; Maria, P. C.; Massi, L.; Mayeux, C.; Burk, P.; Tammiku-Taul, J. Cesium Cation Affinities and Basicities. Int. J. Mass Spectrom. 2007, 267, 7-23.

(32) Laurence, C.; Gal, J. F. Lewis Basicity and Affinity Scales: Data and Measurement; John Wiley and Sons: Chichester, U.K., 2009.

(33) Hoyau, S.; Norrman, K.; McMahon, T. B.; Ohanessian, G. A Quantitative Basis for a Scale of $\mathrm{Na}^{+}$Affinities of Organic and Small Biological Molecules in the Gas Phase. J. Am. Chem. Soc. 1999, 121, 8864-8875.

(34) Armentrout, P. B.; Rodgers, M. T. An Absolute Sodium Cation Affinity Scale: Threshold Collision-Induced Dissociation Experiments and Ab Initio Theory. J. Phys. Chem. A 2000, 104, 2238-2247.

(35) Perry, R. A.; Rowe, B. R.; Viggiano, A. A.; Albritton, D. L.; Ferguson, E. E.; Fehsenfeld, F. C. Laboratory Measurements of Stratospheric Sodium Ion Reactions. Geophys. Res. Lett. 1980, 7, 693696.

(36) Rodgers, M. T.; Armentrout, P. B. Noncovalent Metal-Ligand Bond Energies as Studied by Threshold Collision-Induced Dissociation. Mass Spectrom. Rev. 2000, 19, 215-247.

(37) Burk, P.; Koppel, I. A.; Koppel, I.; Kurg, R.; Gal, J.-F.; Maria, P.C.; Herreros, M.; Notario, R.; Abboud, J. L. M.; Anvia, F.; Taft, R. W. Revised and Expanded Scale of Gas-Phase Lithium Cation Basicities. An Experimental and Theoretical Study. J. Phys. Chem. A 2000, 104, 2824-2833.

(38) Austin, C. A.; Rodgers, M. T. Intrinsic Affinities of Alkali Metal Cations for Diaza-18-Crown-6: Effects of Alkali Metal Cation Size and Donor Atoms on the Binding Energies. Int. J. Mass Spectrom. 2015, 377, 64-72.

(39) Fujii, T. Alkali-Metal Ion/Molecule Association Reactions and Their Applications to Mass Spectrometry. Mass Spectrom. Rev. 2000, 19, 111-138.

(40) Feng, W. Y.; Gronert, S.; Lebrilla, C. The Lithium Cation Binding Energies of Gaseous Amino Acids. J. Phys. Chem. A 2003, 107, 405-410.

(41) Boughlala, Z.; Fonseca Guerra, C.; Bickelhaupt, F. M. Alkali Metal Cation Affinities of Anionic Main Group-Element Hydrides Across the Periodic Table. Chem. - Asian J. 2017, 12, 2604-2611.

(42) Boughlala, Z.; Fonseca Guerra, C.; Bickelhaupt, F. M. Alkali Metal Cation versus Proton and Methyl Cation Affinities: Structure and Bonding Mechanism. ChemistryOpen 2016, 5, 247-253.

(43) Baerends, E. J.; Ziegler, T. J.; Autschbach, J.; Bashford, D.; Bérces, A.; Bickelhaupt, F. M.; Bo, C.; Boerritger, P. M.; Cavallo, L.; Chong, D. P.; et al. Computer code ADF2013, SCM, Theoretical Chemistry; Vrije Universiteit: Amsterdam, The Netherlands, https:// www.scm.com.

(44) te Velde, G.; Bickelhaupt, F. M.; Baerends, E. J.; Fonseca Guerra, C.; van Gisbergen, S. J. A.; Snijders, J. G.; Ziegler, T. Chemistry with ADF. J. Comput. Chem. 2001, 22, 931-967.
(45) Boerrigter, P. M.; te Velde, G.; Baerends, J. E. ThreeDimensional Numerical Integration for Electronic Structure Calculations. Int. J. Quantum Chem. 1988, 33, 87-113.

(46) te Velde, G.; Baerends, E. J. Numerical Integration for Polyatomic Systems. J. Comput. Phys. 1992, 99, 84-98.

(47) van Lenthe, E.; Baerends, E. J. Optimized Slater-Type Basis Sets for the Elements 1-118. J. Comput. Chem. 2003, 24, 1142-1156.

(48) Slater, J. C. A Simplification of the Hartree-Fock Method. Phys. Rev. 1951, 81, 385-390.

(49) Vosko, S. H.; Wilk, L.; Nusair, M. Accurate Spin-Dependent Electron Liquid Correlation Energies for Local Spin Density Calculations: A Critical Analysis. Can. J. Phys. 1980, 58, 1200-1211.

(50) Perdew, J. P. Erratum: Density-Functional Approximation for the Correlation Energy of the Inhomogeneous Electron Gas. Phys. Rev. B: Condens. Matter Mater. Phys. 1986, 34, 7406.

(51) Perdew, J. P. Density-Functional Approximation for the Correlation Energy of the Inhomogeneous Electron Gas. Phys. Rev. B: Condens. Matter Mater. Phys. 1986, 33, 8822-8824.

(52) Becke, A. D. Density-Functional Exchange-Energy Approximation with Correct Asymptotic Behavior. Phys. Rev. A: At., Mol., Opt. Phys. 1988, 38, 3098-3100.

(53) Swart, M.; Snijders, J. G. Accuracy of Geometries: Influence of Basis Set, Exchange-Correlation Potential, Inclusion of Core Electrons, and Relativistic Corrections. Theor. Chem. Acc. 2003, $110,34-41$

(54) van Lenthe, E.; Baerends, E. J.; Snijders, J. G. Relativistic Regular Two-Component Hamiltonians. J. Chem. Phys. 1993, 99, $4597-4610$

(55) Atkins, P.; de Paula, J. Atkins' Physical Chemistry; Oxford University Press: Oxford, U.K., 2010.

(56) Jensen, F. Introduction to Computational Chemistry, 2nd ed.; John Wiley and Sons: West Sussex, U.K., 2007.

(57) Bickelhaupt, F. M.; Baerends, E. J. Kohn-Sham Density Functional Theory: Predicting and Understanding Chemistry. Rev. Comput. Chem. 2007, 15, 1-86.

(58) Ziegler, T.; Rauk, A. On the Calculation of Bonding Energies by the Hartree Fock Slater Method. Theor. Chim. Acta 1977, 46, 110.

(59) Ziegler, T.; Rauk, A. A. Theoretical Study of the EthyleneMetal Bond in Complexes between Copper(1+), Silver(1+), Gold$(1+)$, Platinum(0) or Platinum(2+) and Ethylene, Based on the Hartree-Fock-Slater Transition-State Method. Inorg. Chem. 1979, 18, $1558-1565$.

(60) Ziegler, T.; Rauk, A. Carbon Monoxide, Carbon Monosulfide, Molecular Nitrogen, Phosphorus Trifluoride, and Methyl Isocyanide as $\sigma$ Donors and $\pi$ Acceptors. A Theoretical Study by the HartreeFock-Slater Transition-State Method. Inorg. Chem. 1979, 18, 17551759.

(61) Bickelhaupt, F. M.; Ziegler, T.; von Ragué Schleyer, P. CH3• Is Planar Due to $\mathrm{H}-\mathrm{H}$ Steric Repulsion. Theoretical Study of MH3 and $\mathrm{MH} 3 \mathrm{Cl}(\mathrm{M}=\mathrm{C}, \mathrm{Si}, \mathrm{Ge}, \mathrm{Sn})$. Organometallics 1996, 15, 14771487.

(62) Ryno, S. M.; Risko, C.; Brédas, J.-L. Noncovalent Interactions and Impact of Charge Penetration Effects in Linear Oligoacene Dimers and Single Crystals. Chem. Mater. 2016, 28, 3990-4000.

(63) Krapp, A.; Bickelhaupt, F. M.; Frenking, G. Orbital Overlap and Chemical Bonding. Chem. - Eur. J. 2006, 12, 9196-9216.

(64) Bickelhaupt, F. M.; DeKock, R. L.; Baerends, E. J. The Short $\mathrm{N}-\mathrm{F}$ Bond in $\mathrm{N}_{2} \mathrm{~F}^{+}$and How Pauli Repulsion Influences Bond Lengths. Theoretical Study of $\mathrm{N}_{2} \mathrm{X}^{+}, \mathrm{NF}_{3} \mathrm{X}^{+}$, and $\mathrm{NH}_{3} \mathrm{X}^{+}(\mathrm{X}=\mathrm{F}, \mathrm{H})$. J. Am. Chem. Soc. 2002, 124, 1500-1505.

(65) Kasende, O. E.; Muya, J. T.; Broeckaert, L.; Maes, G.; Geerlings, P. Theoretical study of the regioselectivity of the interaction of 3-methyl-4-pyrimidone and 1-methyl-2-pyrimidone with Lewis acids. J. Phys. Chem. A 2012, 116, 8608-8614.

(66) De Proft, F.; Van Alsenoy, C.; Geerlings, P. Ab Initio Study of the Endohedral Complexes of C60, Si60, and Ge60 with Monoatomic Ions: Influence of Electrostatic Effects and Hardness. J. Phys. Chem. 1996, 100, 7440-7448. 
(67) Geerlings, P.; De Proft, F.; Langenaeker, W. Conceptual Density Functional Theory. Chem. Rev. 2003, 103, 1793-1874.

(68) Goesten, M. G.; Rahm, M.; Bickelhaupt, F. M.; Hensen, E. J. M. Cesium's Off-the-Map Valence Orbital. Angew. Chem., Int. Ed. 2017, 56, 9772-9776.

(69) Rogachev, A. Y.; Miao, M.; Merino, G.; Hoffmann, R. Molecular $\mathrm{CsF}_{5}$ and $\mathrm{CsF}_{2}{ }^{+}$. Angew. Chem., Int. Ed. 2015, 54, 82758278.

(70) Valadbeigi, Y. CBS-Q and DFT Calculations of Lithium and Sodium Cations Affinities and Basicities of 60 Organic Molecules. Comput. Theor. Chem. 2016, 1091, 169-175.

(71) Smith, S. F.; Chandrasekhar, J.; Jorgensen, W. L. Ab Initio Study of Acid-Base Interactions. Proton, Lithium, and Sodium Affinities of First- and Second-Row Bases. J. Phys. Chem. 1982, 86, 3308-3318. 